\title{
A Traumatic Asphyxia After a Construction Accident
}

\author{
Özlem Özdemir ${ }^{1}$, Atakan Savrun ${ }^{2}$ \\ ${ }^{1}$ Department of Internal Medicine, Faculty of Medicine, Ordu University, Ordu, Turkey \\ ${ }^{2}$ Department of Emergency, Faculty of Medicine, Ordu University, Ordu, Turkey \\ Received: 18 April 2018 Accepted: 23 April 2018, Published online: 28 August 2018 \\ (C) Ordu University Institute of Health Sciences, Turkey, 2018
}

\begin{abstract}
The traumatic asphyxia is defined as cyanosis, petechiae on the face, neck, upper extremities and upper parts of the thorax and subconjunctival haemorrhage, retinal edema due to blunt thoracic trauma. Traumatic asphyxia is a rare syndrome. In cases of traumatic asphyxia, different neurological symptoms can be seen to be proportional to the severity of trauma. Treatment is conservative, but depends on the severity of prognostic-related injuries. In this article, we present a case of traumatic asphyxia syndrome in a 35-year-old male patient who had a traumatic asphyxia syndrome resulting from a construction accident. And in this context the literature, diagnosis, treatment and prognosis were discussed.

Key words: Thoracic trauma, traumatic asphyxia, treatment, prognosis
\end{abstract}

Address for correspondence/reprints:

Özlem Özdemir

Telephone number: +90 (535) 6819716

E-mail: ozlemtfl@hotmail.com

DOI: $10.19127 / \mathrm{mbsjohs.416716}$

\section{Introduction}

Traumatic asphyxia is a clinical condition due to increased venous pressure after severe, compressive, blunt and sudden chest trauma. This syndrome is also called acute thoracic compression syndrome or ecchymatic mask (Senoglu et al., 2006). Traumatic asphyxia is a rare syndrome, but mortality is high in proportion to the energy of trauma. In these cases cyanosis, petechiae, subconjunctival haemorrhage, retinal edema and different neurological findings may be presented (Guitron et al., 2009). 


\section{Case}

A thirty-five-year-old male patient was admitted to the emergency room with the contraction of the right arm and the thorax and the region from the shoulder to the neck by the heavy body overturning. At the physical examination; the conscious is off (Glasgow Coma Score: E2 M4 V2), blood pressure $102 / 74 \mathrm{mmHg}$, heart rate 115 pulses / min, respiratory rate 23 breaths / $\mathrm{min}$; the $\mathrm{spO} 2$ was $84 \%$ and the pAO2 was $65 \mathrm{mmHg}$ in blood gas analysis. The head-neck and upper chest wall were cyanotic, edematous in appearance, with common petechial rash and subconjunctival haemorrhage. On the right side of the thorax, there were findings of a sail chest (flail chest) on the upper wall. Respiratory voices decreased in the right lung areas, and natural on the left. On chest X-ray; pneumothorax was detected. Due to respiratory distress, tube thoracostomy and closed underwater drainage were performed from the right side. The case was taken in mechanical ventilation support in pressure controlled mode. Computed tomography examination of the brain and routine laboratory values were usual. On the second day the consciousness was opened, on the seventh day the spontaneous respiration was passed and he was extubed on the eighth day. Because of the pneumothorax dimension, the thorax tube which was clamped on the ninth day was completely removed on the 10th day. The patient was discharged on the 14 th day without any problems.

\section{Discussion}

Traumatic asphyxia first was described in 1837 by autopsy findings by Oliver d'Angers and named Perthe's syndrome. It is also called acute thoracic compression syndrome or ecchymatic mask. Although it is rare, its incidence is not known exactly. Although it usually develops due to blunt chest trauma, it may develop occasionally due to conditions that lead to an extended valsalva maneuver such as severe vomiting, pertussis, epilepsy and severe asthma (Besson et al., 1989). Asphyxia is of Greek origin as a word, meaning "unable to get a pulse or lack of pulse" and "drowning". The main problem is the sudden and deep oxygen deficiency of the tissues. Although the physiopathologic mechanism of traumatic asphyxia is not fully known, it is thought that the effect of pressure on the heart, mediastinum due to acute trauma is responsible (Lee MC et al., 1991). During the trauma, four factors come into play to form this syndrome. These; deep inspiration, closed glottis, thoracoabdominal effort, and thoracoabdominal compression which leads to directing the blood to the cervicofacial area. (Çobanoğlu and Yalçınkaya, 2010). An increase in intrathoracic pressure with an acute mechanism results in an acute increase in pressure in the superior and inferior vena cava, mediastinal veins and right atrium. Depending on the acutely increased pressure, the blood primarily goes to the capless veins in the head and neck and causes a typical appearance in the clinic. Depending on the high pressure coming from the acute mass, the sudden increased pressure in the large veins is transmitted to the cervicofacial venules and then to the small venules and capillaries. Depending on this situation, blood escapes out of the vein. The valve system in the veins prevents the pressure build-up from entering the acute field. Traumatic asphyxia is seen only in the area where there are cervicofacial veins in which veins without a valve system are present (Kutlu CA, 2003). As a result, a cyanotic hemorrhagic appearance, scleral and subconjunctival hemorrhages and petechiae in the cranio-cervical region develop in the head and neck. The clinical picture varies according to the severity and duration of the trauma. Depending on the mechanism and location of the trauma, skin, eye, brain, nose, airways, breast, gastrointestinal tract and abdominal region findings can be found. Subconjunctival petechiae and subcutaneous haemorrhage are frequently seen. Especially in the head and neck region, cyanosis is common. Language, lips, mouth and pharyngeal petechia can be followed. Haemorrhage is frequently seen in the subconjunctival region with damage at the retina, vitreous and optic nerve (Sandiford JA et al., 1974). Bilateral optic disc edema has also been reported (Esme H. et al., 2006). Because of the blunt thoracic trauma, pathologic findings such as sail chest, rib fracture, lung contusion, hemopneumothorax may accompany the patients but any thoracic pathology may be observed too. An important part of the cases may be accompanied by cardiac injury. An important part of the cases may be accompanied by cardiac injury. Depending on the severity, duration and localization of the trauma, neurological findings in the patients may show different clinical tables ranging from mild symptoms to coma. Neurological symptoms are loss of consciousness, disorientation, agitation, brachial plexus injury without spinal cord injury, quadriplegia and coma. These findings are thought to be due to hypoxic damage such as cerebral edema and haemorrhage (Sandiford JA et al.,1974). The most important approach in patients with traumatic asphyxia is the supportive treatment. 
Frequent arterial blood gas, oxygen saturation should be monitored and acute respiratory support should be planned in patients. Increase of the intracranial pressure should be prevented by increasing bedhead 30 degrees (Eken C. et al., 2009). Mild cases can be fully recoverable. Even patients with neurological findings due to brain edema were reported to recover within 1-2 weeks of supportive treatment. Mortality and morbidity are proportional to the presence and severity of cardiovascular, pulmonary, and neurological injuries (Lee MC et al., 1991).

\section{Conclusion}

Traumatic asphyxia is a rare condition. Prognosis is often due to the duration, severity and localization of the trauma. A rapid and careful approach in cases of traumatic asphyxia provides a reduction in the mortality and morbidity of patients. The emergency department is a clinic where rare but acute and lifethreatening cases are seen. Therefore, treatments to prevent increased intracranial pressure, oxygen inhalation therapy, efficient ventilation, intravenous hydration should be started as soon as possible in the similar cases.

Patient.Approval: Approval was received for this study from the patient.

Peer-review: Externally peer-reviewed.

Author Contributions: Concept - Ö.Ö., S.A.; Design- Ö.Ö., S.A; Supervision- Ö.Ö., S.A.; Funding- Ö.Ö., S.A.; Materials- Ö.Ö., S.A.; Data Collection/Data Process- Ö.Ö.; Analyze or Comment- Ö.Ö., S.A., Literature Scanning- Ö.Ö.; S.A; Writer of Paper- Ö.Ö.; Critical Review- Ö.Ö.

Conflict of Interest: No conflict of interest was declared by the authors.

Financial Disclosure: The author declared that this study hasn't received no financial support.

\section{References}

Besson A, Saegesser F, editors. The acute thoracic compression syndrome: so-called traumaticasphyxia. In: A colour atlas of chest trauma and assosiated injuries. Vol 1. Paperback ed. Netherlands: Wolfe Medical Publications Ltd; 1989. p. 117-21.

Çobanoğlu U, Yalçınkaya İ. Thorax injuries. National Trauma Emergency Surgery Journal 2010: 16 (1): 77-83

Eken C, Y1git O. Traumatic asphyxia: a rare syndrome in trauma patients. Int $\mathbf{J}$ Emergency Medicine 2009; 2: 255-5

Esme H, Solak O, Yurumez Y, Ermis S, Yaman M, Fidan F. Perthes syndrome associated with bilateral optic disc edema. Can J Ophthalmol 2006; 41: 780-82

Gorenstein L, Blair GK, Shandling B. The prognosis of traumatic asphyxia in childhood. J Pediatric Surgery 1986; 21: 753-6

Guitron J, Huffman LC, Howington JA, LoCicero III $\mathrm{J}$. Blunt and Penetrating Injuries of the Chest Wall, Pleura, and Lung. In: Shields TW, Locicero III J, Reed CE, Feins RH, eds. General Thoracic Surgery. 7th ed. Philadelphia: Lippincott Williams and Wilkins; 2009: 891-902

Kutlu CA. Pulmonary injuries. In: Yuksel M, Cetin $\mathrm{G}$, at al. Thorax trauma. Istanbul: Turgut publishing company; 2003: 34-39.

Lee MC, Wong SS, Chu JJ, et al. Traumatic asphyxia. Annual Thoracic Surgery 1991; 51: 8688

Sandiford JA, Sickler D. Traumatic asphyxia with severe neurological sequelae. J Trauma 1974; 14: 805-10

Şenoğlu N, Öksüz H, zincirci B, Ezberci M, Yasım A. Severe traumatic asphyxia: two case reports literature review.. Turkish Thoracic Cardiovascular Surgery Journal 2006; 14(1): 7881 